\title{
The Realities of Period Poverty: How Homelessness Shapes Women's Lived Experiences of Menstruation
}

\author{
Shailini Vora
}

\section{INTRODUCTION}

Being on your period is the worst time for a woman to be homeless - it gives you that extra blow. - Simran

While estimates vary, in the US, 553,000 people are experiencing homelessness on any single night (US Department of Housing and Urban Development 2018, 1), while this figure in the UK is roughly 320,000 (Shelter 2018). Single women make up over a quarter of the users of homeless services in the UK (Homeless Link 2017, 23), and this percentage is similar in the US, with $28 \%$ of people experiencing homelessness being single women (US Department of Housing and Urban Development 2018, 11). These numbers are likely to be significant underestimates given the number of women experiencing "hidden homelessness" (Watson with Austerberry 1986), who do not access homeless services but stay in other temporary forms of accommodation such as the houses of relatives, friends, hostels, or bed and breakfasts. There are millions of people living in makeshift, precarious housing situations who lack complete and reliable access to private, safe and clean water, and sanitation facilities (see also McCarthy and Lahiri-Dutt [Chapter 3] in this volume).

The experiences of menstruation by people who are homeless, however, has been historically overlooked by the public, civil society actors, policy makers, and academics. Much progress has been made in recent years within academic literature to deepen our understanding of the multifaceted issue of women's homelessness, through studies of health, abuse, trauma, and specific policy responses 
and intervention (for example, Padgett et al. 2006; Vijayaraghavan et al. 2012; Schutt and Garrett 2013). Taking into account the specific exclusions and traumas that are faced by women who are homeless, this literature is very productive and useful in order to work toward alleviating these challenges and providing gender-specific support for recovery. The topic of menstruation, however, is expressed only as a factor of the reproductive health of women who are homeless, as outlined by medical narratives (for example Ensign 2001). To my knowledge, there has been no explicit study conducted on the ways in which women in precarious housing situations understand menstruation in relation to their own corporealities and subjectivities (see Sebert Kuhlmann et al. 2019).

The growing presence of a class-aware menstrual activist movement, and the subsequent practical initiatives that have emerged to alleviate the challenges faced by marginalized women are seeking to reverse this inattention. The energy and persistence of grassroots campaigns have prompted responses at local government levels to the issue of period poverty. Period poverty, a term used mostly in the UK, refers to the state in which people who menstruate find themselves without the financial resources to access suitable menstrual products.

Despite this burgeoning movement within activist spaces, academic scholarship on menstruation has been largely inattentive to the socioeconomic diversity of women, failing to take into account how their experiences and identities transform the ways in which they relate to their menstruating bodies. Existing literature within the social sciences about menstruation has been focused on the issues of stigma, commodification, menstrual health, and medicalization (Kissling 2006; Johnston-Robledo and Stubbs 2013; Lahiri-Dutt 2015). These have been extremely productive for the understanding of the politics of menstruation, however many Anglo-American texts fail to address intersectionality. Menstrual literature in the Global North has been written about, and for, white, ${ }^{1}$ middle-class, cisgender women (Johnston-Robledo and Stubbs 2013, 4 ), or in a developmental context, addressing the exclusions of women living in poverty in the Global South (for example Dhingra, Kumar, and Kour 2009; Boosey, Prestwich, and Deave 2014; Smiles, Short, and Sommer 2017). The situated-ness of these debates, it seems, is polarized: either addressing the privileged middle classes in the Global North or the socioeconomically marginalized in the Global South. However, disenfranchised women within societies in the West have been neglected: those who may not have financial or material resources to manage menstruation in a way that meets societal expectations. ${ }^{2}$ It is imperative, therefore, in order to work toward a truly emancipatory and revolutionary feminism, that the politics of difference is included within gendered debates. How do socioeconomic disparities among women affect the way that they relate to themselves as menstruators?

This chapter therefore attempts to bring about a 'class consciousness' (bell hooks 2000) in the mapping of the lived experience of menstruation, through an increased understanding of the experiences of women who are homeless. It offers an insight to the ways in which women experiencing homelessness understand and negotiate their menstrual bodies within contexts of limited 
financial and material resources. This study explores the scale of the personal, offering a phenomenological insight into their experiences. This contrasts with atheoretical texts within academic literature that seek to homogenize homeless populations (DeVerteuil, May, and Von Mahs 2009, 658). It also attempts to critically analyze the current policy and third sector initiatives across the Global North that hope to minimize the effects of period poverty upon marginalized menstruators through practical interventions.

\section{Phenomenology, Emotions, And the Body}

Phenomenology is the theoretical starting point for my exploration of the rich depths of the menstrual experiences of women who are homeless. I give authority to lived experience to 'capture life as it is lived' (Moran 2000, 5). Phenomenology attends to a complex interrelatedness between the material flesh, the body, and the consciousness of the human subject (Merleau-Ponty 2002,5 ), and it is in the footsteps of this theory that I explore the experiential, affective and contingent nature of the lives of marginalized women throughout menstruation.

I attempt to generate this understanding by prioritizing the feelings and emotions that tint perceptions and embodied experience. Not only is emotional experience important to paint a rich portrayal of the modalities of menstruators who are homeless, but as a feminist narrative, it frames 'the personal as political' (Pile 2010,7). The privileging of emotional experience and understandings of the self (Bondi 2005, 6) allows feminist geographers to unpick the felt complexities of gendered experience (Pile 2010,7).

However, by focusing on the realm of the immaterial, I do not want to neglect the fleshy ontology of the body (Grosz 1994, ix). While phenomenology and emotional geography foreground the body as the site of unique experience, scholars "still often fail to talk about a body that breaks its boundaries - urinates, bleeds, vomits, farts, [and] engulfs tampons" (Longhurst 2001, 23). A dismissal of fleshy corporeality denies the agency of the material body itself. If it is true that a person lives through their body, then it is through the freedoms and restrictions of their bodily capacities and mobility that this living occurs (Young 2005, 16).

\section{Bodies on the Borderline}

The normal body is not a bleeding body. Encounters with bodily fluids provoke averse responses such as nausea, disgust, and horror (Kristeva 1982,3). A body threatening to burst its boundaries and give birth (Longhurst 2000, 455 ), leak milk from her breasts (Boyer 2012, 553) and spill blood from between her legs (Young 2005, 97) is viewed with horror and fascination (Kristeva 1982, 3). It is this cultural representation of a sticky, messy femininity that places menstruating women at the borders of social legitimacy. Any manifestation, therefore, of menstruation, whether it be a bloody stain 
or an emotional expression, suggest that "women are not men, cannot be men, and as so cannot exist in the world as men do" (MacDonald 2007, 348). It is through the concealment of this process that menstruators claim normalcy.

The abject is also embodied by the homeless woman. She represents a seepage beyond the boundaries of 'acceptable' social life (Butler 1993, xiii). Her body is subject to stigmatization and marginalization; in the public imaginary she is cast as 'dirty,' 'deviant,' and 'transgressive' (Radley, Hodgetts, and Cullen 2006, 438). Rough sleepers, in the public imagination, are "lives who are not considered to be 'lives', and whose materiality is understood not to 'matter'" (Meijer and Prins 1998, 281).

What happens when the abject fluid comes to plague the abject body? A stark paradox appears for a woman sleeping in the streets, constantly within the public gaze, attempting to uphold the privacy of her flowing, leaky body. Against this background, my research is guided by three questions: (1) How do women experiencing homelessness negotiate the emotional and affective experiences of menstruation? (2) How is menstruation materially managed? and (3) To what extent are third sector initiatives in the US and UK effective in addressing the challenges marginalized menstruators face?

\section{Methodology}

For the case study, primary research interviews were undertaken with 40 women in the city of Bristol, UK, who were accessing a range of services that support vulnerable people in precarious housing situations for their various needs: shelters, drug support groups, day centers, and food banks. Bristol, located in the south west of the UK, has a significant homeless population, with statutory homelessness being over twice the national average (Gouk 2017). Rough sleeping has increased consistently over the last five years (Yong 2017) due to pernicious austerity measures by the UK government and an on-going housing crisis. Private rental costs in Bristol are the highest in the UK outside of London, and the area has $9 \%$ less social housing than the national average (D'Arcy 2017, 32).

In order to analyze the effectiveness of charitable initiatives in tackling period poverty, I use two methods. I firstly compare the needs highlighted by women in the interviews to the needs addressed by activities undertaken by charitable groups, and secondly attempt to unpick the extent to which these initiatives seek to resolve underlying, long-term issues such as breaking down stigmas around menstruation. This research has been undertaken through my first-hand experience as working for No More Taboo, a social enterprise seeking to alleviate the issues around period poverty in the UK, and through secondary research using online sources.

An important caveat must be highlighted, however, before the trajectory of this study continues. Menstruation is not a uniquely female experience. "Not all women menstruate, and not only women menstruate" (Bobel 2010, 11). 
Menopause and external factors that can alter the menstrual cycle, such as contraception, body weight, and stress (Stöppler 2015) create a large group of women who do not menstruate. In contrast, transgender men and intersex people are not female, yet can still menstruate (Bobel 2010, 12). For the purpose of this study, however, the experience of cisgender, menstruating women will be explored as all the women interviewed identify as such.

\section{Emotional Experiences of Menstruation}

For me, my period means problems. Mental and physical problems. (Safiya)

The majority of the women interviewed, when asked to describe their experience of menstruation, framed their monthly bleed as an emotional and painful period, rife with negative sensations, such as irritability, stress, vulnerability, and symptoms of low mood as well as anxiety and depression.

Cheryl expresses the need for rest and privacy, despite finding herself in a state of constant flux due to her insecure housing situation:

It's quite tough and it's embarrassing when you think you're smelly. I feel that people know that I'm on, even if I know they don't know, I think they do! [Menstruation] makes me irritable, it makes me tired and it gives me back problems, and I can't move, and obviously in the situation that I'm in in the moment, it's quite difficult.

She accounts experiences of 'felt stigma' (Scambler 2009, 445), constructing her body as malodourous and deviant. The heightened awareness of her menstrual self as potentially disgusting within the social sphere creates internalized sensations of shame and guilt. She anticipates and imagines people's adverse reactions to her menstruating body, and this threat causes her discomfort and embarrassment. She describes herself as more emotionally sensitive and drained, while acknowledging her precarious housing situation-sleeping on the sofas in the houses of friends and family. This highlights the tension between her homeless body and menstrual body. While she is menstruating she "can't move," while simultaneously having to be constantly mobile, changing from one house to another. This mobility undermines her ability to self-care and fully manage the pains and the stresses that she documents as part of her menstruating experience. Her corporeal vulnerabilities are intensified through her homeless situation.

Mary-Ann extends this notion of 'felt stigma' and applies it to her status as a woman experiencing homelessness. "You want to be having a wash, but you can't. When you're homeless, you're embarrassed about your situation anyway." The embarrassment Mary-Ann feels of her leaky, menstruating body is exacerbated by her lack of stable accommodation. Mary-Ann rearticulates common notions of both the homeless (Gerrard and Farrugia 2015, 2220) and the menstrual body (Lee and Sasser-Coen 2015, 10) as messy, dirty and impure. Her embodiment of both abject categories places her in a doubly 
stigmatized position, her body marginalized by a culture that eschews and rejects manifestations of poverty and leaky corporeality.

Discursive debates seem far removed from the everyday realities of life on the streets, however they manifest in the material ways that the bodies of menstruating, marginalized women are perceived and controlled, not only by external disciplinary forces but also by their internal, self-regulatory actions. Both Cheryl and Mary-Ann attempt to uphold culturally dominant rituals of self-purification and self-regulation, attempting to conceal their menstruating status and remain within the margins of acceptable cleanliness. To a woman restricted by her mobility and financial resources, a socially legitimate, clean, concealed period is difficult to attain.

\section{Affective Management Strategies}

The emotional-corporeal experience of menstruation influences the everyday routines of the women and spaces in which they inhabit. They use "tactical rationalities" (Cloke, May, and Johnsen 2008, 243) to actively negotiate their menstrual state while simultaneously accommodating for their marginalized position as women experiencing homelessness.

\section{Warmth, Comfort, and Safety}

Many of the interviewees highlighted warmth and comfort as an important factor to alleviate negative symptoms of menstruation. Naomi emphasizes the significance of café spaces; when feeling dispirited, with painful menstrual cramps, she would "practically live in cafés. They're warm and they've got comfy sofas." The participants considered spaces such as multi-functional day centers extremely useful in this respect, considering that "if you stay too long [in a café], they ask you to buy something or make you leave" (Naomi).

Kim, having slept on the streets for the past month, says that "places like this [a Christian day center] give people comfort. So they know they're safe an' that. 'Cause on the streets it's not safe." She echoes the narratives of many female rough sleepers in the cartographies of fear within urban spaces (Radley, Hodgetts, and Cullen 2006, 441), and finds refuge and solace in the spaces of the center, where she can socialize and receive free tea and warm food. This highlights the importance of homelessness organizations and shelters as "spaces of care" (Johnsen, Cloke, and May 2005, 790), not only offering nutritional sustenance, but an opportunity to alleviate emotional isolation and provide physical safety.

However, this 'space of care' within Mary-Ann's life-world forms only a fraction of her affective resources. While she was menstruating, she also had to rely on existing social networks and friendships. "I've been sleeping in the town centre, but 'cause I'm on ${ }^{3}$ now, I slept at my mate's last night 'cause I couldn't take no more" (Mary-Ann). This is not a unique occurrence. Adesola, has nowhere to go in the daytime, as the night shelter in which 
she is temporarily residing closes its doors throughout the day. She employs social and affective networks of housed friends to stay comfortable and warm throughout the day while she is menstruating: "I have got some good people on my side, I'll turn up and say 'right, I need a couple of hours.' They'll let me go round and sit there with a hot water bottle." The participants who sought the help of friends and acquaintances did not express any qualms for doing so. For the disconnected woman, without such affective networks, she must take rest and refuge within the public spaces of the city: "When it was hurting a lot, I just had to sit down for a bit, just on the bench. I had nowhere else I could go" (Rhian).

\section{Yearning for Privacy}

Women experiencing homelessness reside in spaces that are not theirs. Shopping centers, libraries, and parks are common public spaces that are used by women who are homeless to take respite (Reeve, Casey, and Goudie 2006, 7). Shelters and couches in friends' homes barely offer true privacy. A stable, private space is required for the intimate act of menstrual management and negotiation of subsequent emotional fluctuations and fatigue. The majority of women interviewed yearned for privacy while menstruating, especially for the act of managing their menstrual flows, as public toilets were deemed "disgusting" (Mia) and "terrible" (Erin). The constant upheaval and mobility of Cheryl's life does not allow her to fully relax, as she would if she had her own, private space. "I'm stopping here and there and everywhere, and I have very severe, heavy periods, so it's very uncomfortable." This sentiment is echoed by Simran: "I would just love to be somewhere . . . and not feel like an intruder." The extreme visibility of homelessness contrasts sharply with the intimacy needed to manage the physical and emotional aspects of menstruation.

\section{Material Menstrual Management}

I haven't used pads, 'cause I haven't had no money. I've had to use toilet paper. (Jennifer)

Menstruators negotiate their periods through its management (Young 2005,103 ), as socially produced scripts of purity and pollution (Douglas $1966,35)$ require its secrecy and concealment. The practical considerations of menstruation were a concern raised by the interviewees. The commodification of sanitary products within Western society means that they come at a cost, a cost that many financially marginalized women, struggling to pay for basic amenities, may not be able to bear. Jennifer documents her socially irregular use of toilet paper, gleaned from public toilets, to ensure that her menstrual blood is absorbed. In her situation, she cannot afford to purchase commodified sanitary products. One participant also spoke of having to occasionally 
shoplift such items, in desperation, echoing a worrying trend in "survival shoplifting" for those in such financial destitution (Hall 2017, 23).

Some women explained that, in "desperate situations" (Jenelle), they would ask for menstrual products in the institutional locations of the spaces in which the interviews took place. Their experiences, however, are varied. In a short-term shelter, Jenelle affirms that "we're pretty lucky here, 'cause they've always got some in stock." She relies on the shelter to provide her the material resources for managing her menstruation. However, Kate, who uses the services of a Christian day center, highlights the inattention to service users' menstrual needs: "Sometimes they have some . . . sometimes they don't. I don't really understand why that is, they should have a lot more considering that it's an obvious priority." One of the functions of the center, to Kate, is the provision of basic amenities that are unobtainable given the financial situation of their female service users. She problematizes the inconsistency of the supply of sanitary products, framing them as an "obvious priority:" the management of an essential, unpredictable and uncontrollable bodily process that has been overlooked by the staff.

Some women, however, were reluctant to ask the staff as they felt it was a shameful subject. "I would never ask, I'd be too embarrassed" (Michelle). Such embarrassment, as described by Michelle, is the result of a persistent socio-cultural stigma surrounding menstruation (Laws 1990). The inability to access products at the shelter also highlights an inadequate system of communication about the availability of menstrual products. Cynthia comments that she does not know "if they give them out here," illustrating a gap between the supply of products to shelters via donations and the actual receipt and usage of the products by service users. ${ }^{4}$

However, in some situations, this embarrassment is present not only due to the shroud of socio-cultural stigma that surrounds menstruation, but also the institutional power relations between the women and those working at the shelters. Emily, a resident at a longer-term shelter, felt uncomfortable discussing her intimate, bodily needs with those employed to regulate and govern her behavior within her living space. "I wouldn't want to say this but it's kind of like a prison here, they come and do their checks to see if you're all right which means coming into the flat, and if they don't hear you they'll come into your bedroom. It's like having a warden, and you don't really want to be like 'please sir, can I have something for my bleeding." Using the analogy of a prison, Emily echoes geographical analyses of shelters as disciplinary institutions through which homeless bodies are governed and controlled (Williams 1996, 85). Nearly every aspect of their lives is subject to scrutiny by the wardens, their finances, their health, and their living space. She resists the total scrutiny of her body by refusing to disclose information about her intimate bodily processes to the staff. The need to ask for products is highlighted as unfair by some participants, due to this regime of bodily control exerted by staff: "I feel like they should be in all toilets, and you can help yourself" (Samantha). 
Embarrassment and the resistance of power relationships within the shelter are not the only rationales for refusing to ask for sanitary products. Frankie states: "It's not their responsibility really. You're supposed to be getting used to providing for yourself again." She believes that menstruation is a personal process that should be managed individually, and views the ability to afford menstrual products as a progression toward being able to support herself economically. The ability to provide for herself again shows the symbolic value of embracing a self-sufficient, economically responsible subjectivity (Farrugia 2011, 82). It lifts her from the marginal zone of the abject (Kristeva 1982, 3 ), and allows her to break away from common perceptions of people who are homeless as 'irresponsible' and 'morally deviant.'

\section{'Alternative' Practices}

The consumption of menstrual hygiene products has become naturalized in Western society, with disposable tampons and pads being the most common method used to manage menstruation. The awareness and use of reusable sanitary products such as washable pads and menstrual cups are now growing as a form of 'alternative' menstrual hygiene management. Despite their popularity and prevalence being trivial in the market compared to disposables (Atkin 2018), demand is rising due to an increasingly environmentally conscious consumer market.

However, the use of such products was not viewed as possible nor desirable for the interviewees. The participants communicated the difficulty in the cleaning of reusable sanitary products due to their constant spatial mobility (for the 'rough sleepers' and the 'hidden homeless' who are constantly moving around the houses of friends and hostels) and the lack of privacy of shared cleaning facilities (for those in shelters). The initial costs of the products were also too steep for the women, who possess limited financial resources. The extent to which the participants can partake in an environmental menstrual feminism, therefore, is extremely limited, due to its complete reliance on women's consumption patterns and privacy of sanitation facilities.

The subjective experiences of the participants are inextricably bound to contradictory tensions that arise between their homeless and menstrual status. The participants embody sensations of moral judgment that arise from the double stigma of menstruation and homelessness. They attempt to find solutions to rid themselves of visceral feelings of impurity which ties them to an abject condition. However, their visibility as women experiencing homelessness within the public gaze and constant spatial mobility diminishes their ability to manage menstruation in the ways they would like to: in privacy, and with a stable, safe place to rest. They improvise and find makeshift ways to ease these tensions through informal networks and homeless institutions, despite framing difficulties in accessing the products. Against this background, the next section of this chapter will move to asking: What are third sector organizations doing to minimize the hurdles faced by the participants? 


\section{Initiatives to Combat Period Poverty}

Civil society has been quick to galvanize attention and support for addressing period poverty, since the issue came into public consciousness (Gharib 2015). Activity has flourished in both the US and the UK within the voluntary sector, working to alleviate the situations of millions of menstruators living in poverty. The majority of such initiatives in both countries adhere to a donation-based approach. Rallying up support from the public, they collect menstrual products (disposable pads and tampons), and donate these unconditionally to soup runs, homeless shelters, domestic violence refuges, schools and foster care agencies. Examples of organizations following this approach include I Support the Girls and \#HappyPeriod in the US, and \#TheHomelessPeriod and Freedom4Girls in the UK.

The provisioning of menstrual products to "spaces of care" (Johnsen, Cloke, and May 2005, 790) for children and adults in vulnerable situations can be lauded for attempting to alleviate the issue in its immediacy. They seek to ameliorate the lives of people experiencing social and financial marginalization, operating through a philosophy of inclusion. There are no conditions in exchange for the receipt of menstrual products. They are supplied without judgment, without questioning the 'deservedness' of the clients (Johnsen, Cloke, and May 2005, 805). This non-interventionist approach (Watts, Fitzpatrick, and Johnsen 2018, 237) provides a valuable safety net for the vulnerable menstruator. These initiatives respond to the situation expressed by Erin: "I mean, what can you do when you've got no money?"

\section{Critiques of the Donation-Based Approach}

Does the free provision of products, however, address the complex, multivalent issues that the participants in this study have expressed? The narratives outlined in this paper indicate that there may need to be a more holistic approach to period poverty if it is to be tackled in a productive and adequate manner. I critique the unconditional donation of products based on three main themes. Firstly, I address issues of communication and agency, and then discuss the importance of breaking taboos surrounding menstruation. I then go on to discuss considerations around the environment and sustainability.

The supply of menstrual products to service users depends wholly on how the homelessness service, whether it be a shelter, day center, or soup run, choose to distribute the products. As seen above, many of the women who participated in the study did not know who to approach to talk about menstruation, and many confessed to feeling embarrassed to speak to members of staff about accessing menstrual products. Others were simply not informed that menstrual products were available. Homelessness services desperately need to improve communication around the availability of menstrual products. In a day center, where interviews for this study were conducted, the staff disclosed that they had received large donations of menstrual products, 
and possessed years' worth of supplies. However, the women interviewed did not know that such products were available to them at this particular service.

How can organizations focused on the distribution of menstrual products ensure that these products reach the hands of those who really need them? As a start, more focus should be put on how many people receive menstrual products, instead of celebrating the number of donations made to shelters and refuges. Supplies within homelessness services should be accessible without needing to ask for them, diminishing the power staff have over service users' bodies. In one emergency night shelter, a range of menstrual products were supplied in every bathroom, and users therefore had the agency to choose which products were suitable for them, and they were not needlessly submitted to admitting their menstrual status to those working in the shelter. Increased efforts should be made among third sector practitioners to deepen understanding of the issues surrounding menstruating while homeless, and to break down the stigma among staff to ensure that they are comfortable with taking the initiative to start the conversation about menstruation. Moreover, menstrual management is not only reliant on physical products, but also on access to safe and private sanitation facilities such as lockable toilets, showers, and laundry services.

In addition to the practical aspects of menstrual management, donation drives fail to make a critical assessment of menstruation, understanding that it is "a bodily process shaped by consumerism and controlled by corporations that disregard both human and environmental health" (Bobel 2010, 105). Disposable sanitary products may contain a host of dioxins, pesticides and chemical fragrances, which are not required to be labeled on the packaging (Spinks 2015). These can cause infections, rashes, and in some cases, death $^{5}$ (Bobel 2010, 108). Not only do disposable menstrual products pose a potential health threat to their users, the disposal of such products generates tons of landfill waste detrimental to the conservation of the planet. The Femcare industry is inherently anti-feminist: "shaming women through ad campaigns, polluting air and water supplies, and producing products that can cause microlacerations of the vaginal wall" (Bobel 2010, 109). The charitable provisioning solution, by encouraging the purchase of products from this industry for donations, offers a short-term stop-gap that benefits multinational corporations much more than the people these organizations try to help (Quint 2017). It is vital that we do not exclude marginalized menstruators from a health- and environmentally-aware menstrual consciousness, and that we actively move toward more emancipatory, transformative interventions in order to empower them to make critical choices about their menstrual management.

Two organizations that attempt to embrace feminist politics to galvanize change are UnTabooed, founded by Diandra Kalish in New York City in 2015 (Period, n.d.), and No More Taboo, founded by Chloe Tingle in Bristol, UK, in the same year. Both focus on providing educational workshops 
to socioeconomically marginalized women and introducing participants to reusable menstrual products such as cups and cloth pads (Period n.d., and author's own knowledge). This approach seeks to provide a comprehensive response to period poverty, incorporating the dissolution of the stigma around menstruation, taking steps to increase social and environmental well-being, and develop bodily self-confidence. Such participatory approaches can help menstruators feel more comfortable about approaching staff members for help, and provide a long-term solution to those who have a certain extent of stability - the use of a menstrual cup or cloth pads that can last years. However, this approach does not help those who are street homeless and constantly mobile. The participants considered their lack of spatial stability a hindrance to the use of reusable products. The paucity of safe, private spaces for hygiene management and other issues outlined in the text above can be, however, brought to the attention of homeless organizations, with the intent to create long-lasting change, and the amenities to manage menstruation in a safe and effective manner.

\section{Toward a Vision of Structural Reform}

Critics argue that the huge scale of resources invested by civil society simply alleviate the symptoms of homelessness without tackling the entrenched issues of destitution and housing, and serve solely as a distraction (Parsell and Watts 2017, 67). Parsell and Watts (2017) argue that the most effective way to ensure that people experiencing homelessness can access the products and services generously given by civil society, whether this be menstrual products, shower facilities or a warm space to rest, is through directly tackling the structural causes of homelessness. Governments must commit to reducing homelessness, transform housing policy and create better employment opportunities for those on the margins of society to be able to reintegrate and form an autonomous, stable part of society. Nevertheless, there are further actions that governments and third sector organizations can take while the problem of homelessness pervades. Menstrual health must be included in indicators of health for people experiencing homelessness, and proper training must be given to service providers about supporting their clients who menstruate. This includes not only the practical aspects, but also the emotional dimensions, taking into account the specific needs of transgender and non-binary people, menstruators with disabilities and the differences between cultures. Huge attitudinal shifts are required to ensure that the topic of menstruation is not erased under the shadow of stigma: one approach to ensuring that stigma is dissipated for further generations is a comprehensive, mandatory curriculum on the topic within schools. 


\section{Conclusions}

This chapter has attempted to disrupt the clean incorporeality of academic discourse (Longhurst 2001, 2) and to engage with the messy worlds of menstruation as experienced by members of a socioeconomically marginalized group: women experiencing homelessness. It has been shaped by the subjectivities of the participants and their consciousness of their being-in-the-world, privileging their bodies as sites of material and emotional flux. A phenomenological lens has allowed a deeper understanding into the sensations, perceptions, and negotiations of the menstrual experiences of women without the means to access safe and stable accommodation.

The erasure of menstruation from public consciousness, due to its stigmatized condition, has uneven consequences on women experiencing homelessness. Menstruation is often overlooked and forgotten in reports addressing the health needs of women experiencing homelessness, and therefore fails to come to the attention of policy makers and service managers. This inattention means that women without adequate financial resources must use irregular, and at times, potentially pathologically unsafe methods of hiding their menstrual blood. The material and discursive narratives of menstruation, combined with the structural and financial exclusions of homelessness have real effects on the everyday realities of the participants' experiences.

The interviews revealed multiple narratives of participants' embodiment as menstruators who are homeless. The participants' sensual, emotional worlds of menstruation are fraught with negative emotion and pain. The stability and privacy needed for the emotional management and self-care that participants felt was necessary while menstruating was unattainable in many situations due to their time-space discontinuities (Rowe and Wolch 1990, 185) caused by homelessness. The dominant social, medical, and commercial scripts of cleanliness, pollution, and stigma that frame menstruation (Patterson 2013,3) were reflected in their responses. However, the conversations also unveiled the multiplicity of strategic rationalities for the management of a fluid, emotional body in a homeless context, within which financial, material, and emotional resources are constrained. The threat of a stigmatic reaction to a bloodstain mobilizes women to undertake certain regimens to ensure that their menstrual blood is constantly hidden, such as prioritizing their spending, shoplifting, or finding alternative sources of menstrual management. However, the ontological devaluation that menstruation confers to women makes it more difficult for the participants to talk to employees of organizations, as it is a topic deemed embarrassing.

A number of initiatives to alleviate these effects on people experiencing homelessness have arisen since 2015 , the majority focused on the provision of free disposable tampons and sanitary towels to shelters and other homelessness services. Despite the profound, positive short-term effect that this strategy could have on the socioeconomically marginalized, it creates a culture of dependence and does not tackle root causes of the stigma of menstruation, 
or seek solutions to the crisis of homelessness through more long-lasting solutions. Other interventions have sought to provide a longer-term outlook, attempting to educate both marginalized menstruators and service providers about the menstrual taboo and alternative methods of menstrual management. However, governments and civil society need to commit further to escalating menstruation in importance when taking into account the health of people experiencing homelessness, ensuring that menstruation is taught in a holistic manner to eliminate the menstrual taboo for following generations, and truly focus on tackling structural inequalities that create the conditions for poverty, homelessness, and destitution to exist.

\section{Notes}

1. There is a growing base of literature on the experiences of menarche and menopause in non-Western societies, for example Aboriginal, Indian and Ethiopian groups, however, in Anglo-American texts, ethnic intersectionality is still limited.

2. A recent study (conducted in St. Louis, Missouri, USA) contributed greatly to diversifying this literature by conducting a study on the menstrual health needs of low-income women, including some participants that were experiencing homelessness (Sebert Kuhlmann et al. 2019).

3. "Being on" is a colloquial mannerism, meaning that she is currently menstruating.

4. This will be discussed in further detail below.

5. Toxic Shock Syndrome (TSS) can be fatal. According to NHS Choices (2014), TSS is "a rare but life-threatening bacterial infection caused by Staphylococcus aureus and Streptococcus pyogenes bacteria . . . a significant proportion of cases occur in women who are on their period and using a tampon".

\section{REFERENCES}

Atkin, Emily. 2018. Why Do Americans Refuse to Give Up Tampons? Accessed January 13, 2019. https://newrepublic.com/article/148432/americans-refusegive-tampons.

Bobel, Chris. 2010. New Blood: Third-Wave Feminism and the Politics of Menstruation. New Brunswick: Rutgers University Press.

Bondi, Liz. 2005. "Making Connections and Thinking through Emotions: Between Geography and Psychotherapy." Transactions of the Institute of British Geographers 30 (4): 433-48.

Boosey, Robyn, Georgina Prestwich, and Toity Deave. 2014. "Menstrual Hygiene Management amongst Schoolgirls in the Rukungiri District of Uganda and the Impact on Their Education: A Cross-Sectional Study." The Pan African Medical Journal 19: 253.

Boyer, Kate. 2012. "Affect, Corporeality and the Limits of Belonging: Breastfeeding in Public in the Contemporary UK." Health \& Place 18 (3): 552-60.

Butler, Judith. 1993. Bodies That Matter: On the Discursive Limits of 'Sex'. New York: Routledge.

Cloke, Paul, Jon May, and Sarah Johnsen. 2008. "Performativity and Affect in the Homeless City." Environment and Planning D: Society and Space 26 (2): 241-63. 
D'Arcy, Conor. 2017. A Western Union: Living Standards and Devolution in the West of England. Accessed January 13, 2019. http://www.resolutionfoundation.org/publications/a-western-union-living-standards-and-devolution-in-the-west-of-england/.

DeVerteuil, Geoffrey, Jon May, and Jürgen Von Mahs. 2009. "Complexity Not Collapse: Recasting the Geographies of Homelessness in a 'Punitive' Age." Progress in Human Geography 33 (5): 646-66.

Dhingra, Rajni, Anil Kumar, and Manpreet Kour. 2009. "Knowledge and Practices Related to Menstruation among Tribal (Gujjar) Adolescent Girls." Studies on EthnoMedicine 3 (1): 43-48.

Douglas, Mary. 1966. Purity and Danger: An Analysis of the Concepts of Pollution and Taboo. New York: Pantheon.

Ensign, Josephine. 2001. "Reproductive Health of Homeless Adolescent Women in Seattle, Washington, USA." Women \& Health 31 (2-3): 133-51.

Farrugia, David. 2011. "The Symbolic Burden of Homelessness: Towards a Theory of Youth Homelessness as Embodied Subjectivity." Journal of Sociology 47 (1): 71-87.

Gerrard, Jessica, and David Farrugia. 2015. "The 'Lamentable Sight' of Homelessness and the Society of the Spectacle." Urban Studies 52 (12): 2219-33.

Gharib, Malaka. 2015. Why 2015 Was the Year of the Period, and We Don't Mean Punctuation. Accessed January 13, 2019. https://www.npr.org/sections/ health-shots $/ 2015 / 12 / 31 / 460726461 /$ why-2015-was-the-year-of-the-periodand-we-dont-mean-punctuation.

Gouk, Annie. 2017. In Numbers-The True Extent of Bristol's Homeless Crisis. Accessed January 13, 2019. http://www.bristolpost.co.uk/news/bristol-news/ numbers-true-extent-bristols-homeless-132603.

Grosz, Elizabeth A. 1994. Volatile Bodies: Toward a Corporeal Feminism. Bloomington: Indiana University Press.

Hall, Tom. 2017. "Citizenship on the Edge: Homeless Outreach and the City." In Lived Citizenship on the Edge of Society, 23-44. Cham: Palgrave Macmillan.

Homeless Link. 2017. “Annual Review 2017.” Accessed January 13, 2019.

hooks, bell. 2000. Where We Stand: Class Matters. New York: Routledge.

Johnsen, Sarah, Paul Cloke, and Jon May. 2005. "Day Centres for Homeless People: Spaces of Care or Fear?” Social \& Cultural Geography 6 (6): 787-811.

Johnston-Robledo, Ingrid, and Margaret L. Stubbs. 2013. "Positioning Periods: Menstruation in Social Context: An Introduction to a Special Issue." Sex Roles 68: $1-8$.

Kissling, Elizabeth Arveda. 2006. Capitalizing on the Curse: The Business of Menstruation. Boulder: Lynne Rienner Publishers.

Kristeva, Julia. 1982. Powers of Horror: An Essay on Abjection. Translated by Leon Roudiez. New York: Columbia University Press.

Lahiri-Dutt, Kuntala. 2015. "Medicalising Menstruation: A Feminist Critique of the Political Economy of Menstrual Hygiene Management in South Asia." Gender, Place \& Culture 22 (8): 1158-76.

Laws, Sophie. 1990. Issues of Blood: The Politics of Menstruation. London: Macmillan.

Lee, Janet, and Jennifer Sasser-Coen. 2015. Blood Stories: Menarche and the Politics of the Female Body in Contemporary US Society. New York: Routledge.

Longhurst, Robyn. 2000. "Corporeographies' of Pregnancy: 'Bikini Babes'." Environment and Planning D: Society and Space 18 (4): 453-72.

- 2001. Bodies: Exploring Fluid Boundaries. London: Psychology Press. 
MacDonald, Shauna M. 2007. "Leakey Performances: The Transformative Potential of the Menstrual Leak." Women's Studies in Communication 30 (3): 340-35.

Meijer, Irene Costera, and Baukje Prins. 1998. "How Bodies Come to Matter: An Interview with Judith Butler." Signs: Journal of Women in Culture and Society 23 (2): 275-86.

Merleau-Ponty, Maurice. 2002. Phenomenology of Perception. London and New York: Routledge \& Kegan Paul.

Moran, Dermot. 2000. Introduction to Phenomenology. London: Routledge.

NHS Choices. 2014. Toxic Shock Syndrome. Accessed April 23, 2016. http://www.nhs. uk/conditions/Toxic-shock-syndrome/Pages/Introduction.aspx.

Padgett, Deborah K., Robert Leibson Hawkins, Courtney Abrams, and Andrew Davis. 2006. "In Their Own Words: Trauma and Substance Abuse in the Lives of Formerly Homeless Women with Serious Mental Illness." American Journal of Orthopsychiatry 76 (4): 461-46.

Parsell, Cameron, and Beth Watts. 2017. "Charity and Justice: A Reflection on New Forms of Homelessness Provision in Australia." European Journal of Homelessness $11(2): 65-76$.

Patterson, Ashly. 2013. "The Menstrual Body.” MA diss., University of New Orleans.

Period. n.d. Absorbing UnTabooed. Accessed January 13, 2019. https://www.period. org/blog/untabooed.

Pile, Steve. 2010. "Emotions and Affect in Recent Human Geography." Transactions of the Institute of British Geographers 35 (1): 5-20.

Quint. 2017. "Never Mind Free Tampons-Schoolgirls Need Education about Their Periods." The Guardian, March 16. Accessed 27 April, 2019. https:// www.theguardian.com/commentisfree/2017/mar/16/free-tamponsschoolgirls-menstruation-period-education.

Radley, Alan, Darrin Hodgetts, and Andrea Cullen. 2006. "Fear, Romance and Transience in the Lives of Homeless Women." Social \& Cultural Geography 7 (3): 437-61.

Reeve, Kesia, Rionach Casey, and Rosalind Goudie. 2006. Homeless Women: Still Being Failed Yet Striving to Survive. Accessed 13 January, 2019. https://www4.shu. ac.uk/research/cresr/sites/shu.ac.uk/files/homeless-women-striving-survive.pdf.

Rowe, Stacy, and Jennifer Wolch. 1990. "Social Networks in Time and Space: Homeless Women in Skid Row, Los Angeles." Annals of the Association of American Geographers 80 (2): 184-204.

Scambler, Graham. 2009. "Health-Related Stigma." Sociology of Health \& Illness 31 (3): 441-55.

Schutt, Russell K., and Gerald R. Garrett. 2013. Responding to the Homeless: Policy and Practice. New York: Springer Science \& Business Media.

Sebert Kuhlmann, Anne, Eleanor Peters Bergquist, Djenie Danjoint, and L. Lewis Wall. 2019. "Unmet Menstrual Hygiene Needs among Low-Income Women." Obstetrics \& Gynecology 133 (2): 238-44.

Shelter. 2018. "Homelessness in Great Britain: The Numbers Behind the Story." Accessed January 13, 2019. https://england.shelter.org.uk/_data/assets/pdf_ file/0020/1620236/Homelessness_in_Great_Britain_-_the_numbers_behind_the_ story_V2.pdf.

Smiles, Dana, Susan E. Short, and Marni Sommer. 2017. "II Didn't Tell Anyone Because I Was Very Afraid': Girls' Experiences of Menstruation in Contemporary Ethiopia." Women's Reproductive Health 4 (3): 185-97. 
Spinks, Rosie. 2015. Disposable Tampons Aren't Sustainable, but Do Women Want to Talk about It? Accessed January 13, 2019. http://www.theguardian.com/ sustainable-business/2015/apr/27/disposable-tampons-arent-sustainable-but-dowomen-want-to-talk-about-it.

Stöppler, Melissa Conrad. 2015. Amenorrhea. Accessed January 13, 2019. http:// www.medicinenet.com/amenorrhea/article.htm.

US Department of Housing and Urban Development. 2018. "The 2018 Annual Homeless Assessment Report (AHAR) to Congress.” Accessed January 13, 2019. https://www.hudexchange.info/resources/documents/2018-AHAR-Part-1.pdf.

Vijayaraghavan, Maya, Ana Tochterman, Eustace Hsu, Karen Johnson, Sue Marcus, and Carol L. M. Caton. 2012. "Health, Access to Health Care, and Health Care Use among Homeless Women with a History of Intimate Partner Violence." Journal of Community Health 37 (5): 1032-39.

Watson, Sophie, and Helen Austerberry. 1986. Housing and Homelessness: A Feminist Perspective. Vol. 86. London: Routledge \& Kegan Paul.

Watts, Beth, Suzanne Fitzpatrick, and Sarah Johnsen. 2018. "Controlling Homeless People? Power, Interventionism and Legitimacy." Journal of Social Policy 47 (2): 235-52.

Williams, Jean Calterone. 1996. "Geography of the Homeless Shelter: Staff Surveillance and Resident Resistance." Urban Anthropology and Studies of Cultural Systems and World Economic Development 25: 75-113.

Yong, Michael. 2017. Number of Rough Sleepers in Bristol Revealed but It's Only the 'Tip of the Iceberg'. Accessed January 13, 2019. https://www.bristolpost.co.uk/ news/bristol-news/number-rough-sleepers-bristol-revealed-916343.

Young, Iris Marion. 2005. On Female Body Experience: "Throwing Like a Girl" and Other Essays. New York: Oxford University Press.

Open Access This chapter is licensed under the terms of the Creative Commons Attribution 4.0 International License (http://creativecommons.org/licenses/ by $/ 4.0 /$ ), which permits use, sharing, adaptation, distribution and reproduction in any medium or format, as long as you give appropriate credit to the original author(s) and the source, provide a link to the Creative Commons license and indicate if changes were made.

The images or other third party material in this chapter are included in the chapter's Creative Commons license, unless indicated otherwise in a credit line to the material. If material is not included in the chapter's Creative Commons license and your intended use is not permitted by statutory regulation or exceeds the permitted use, you will need to obtain permission directly from the copyright holder.

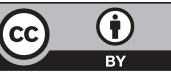

